\section{Is alpha-stat management still justified for deep hypothermic circulatory arrest in adults?}

\section{To the Editor:}

We read with great interest the article titled "Neuropsychologic Outcome After Deep Hypothermic Circulatory Arrest in Adults," by Reich and associates (J Thorac Cardiovasc Surg 199;117:156-63). The authors are to be congratulated for the timely and careful evaluation of deep hypothermic circulatory arrest (DHCA) as a means to protect the central nervous system (CNS) in adults after alpha-stat blood gas management.

Although alpha-stat blood gas management during perfusion hypothermia is widely accepted as the standard, $\mathrm{pH}$-stat management is more physiologic, as observed phylogenically in nature. We would like to bring a few points to the attention of the readership:

The observed limit of 25 minutes as the dividing line between patients with and without sequelae seems to us too short, considering the rather low esophageal temperature of $12^{\circ} \mathrm{C}$ to $15^{\circ} \mathrm{C}$. $\mathrm{We}^{1}$ studied a rabbit model of spinal cord ischemia for 60 minutes during surface-induced hypothermia managed according to $\mathrm{pH}$-stat strategies. We observed that gross neurologic function can be consistently preserved at an esophageal temperature of $29.5^{\circ} \mathrm{C}$. Even though CNS areas involved with neuropsychologic functions might be more vulnerable to ischemia than the spinal cord, the discrepancy seems to be out of proportion. Perfusion hypothermia for 60 minutes at $20^{\circ} \mathrm{C}$ under alpha-stat management without circulatory arrest followed by rewarming causes derangements in glucose use and decreased blood flow, which were attributed to rewarming ${ }^{2}$ but more likely were triggered by the hypothermia per se. ${ }^{3}$ Such alterations may cause injury if long-lasting or severe enough, such as when circulatory arrest is superimposed. Whether $\mathrm{pH}$-stat management would prevent those changes from occurring is not known, but the following observations are noteworthy:

1. Although the major argument for using alpha-stat management during hypothermic perfusion in adults has been to avoid the so-called "luxury perfusion" of $\mathrm{pH}$-stat strategies and the consequent increased likelihood of microembolization, $\mathrm{pH}$-stat management for DHCA in children has been found to result in better neurologic outcome than alpha-stat strategies. ${ }^{4}$ There are no reasons to believe that the outcome would be physiologically or metabolically any different in adults.

2. The shift of the oxyhemoglobin dissociation curve to the left induced by the hypothermia-induced alkalosis is aggravated by the alpha-stat management. The increased affinity of hemoglobin to oxygen results in impairment of oxygen delivery, rendering the tissues hypoxic or anoxic despite adequate blood $\mathrm{PO}_{2}$.

3. Alpha-stat management will result in extracellular alkalinity that has been found to exacerbate excitotoxic neuronal injury by sensitizing neurons to ischemic injury and to potentiate reperfusion injury. ${ }^{5}$

4. On the contrary, mild acidosis, which may be obtained by $\mathrm{pH}$-stat management, decreases $\mathrm{Ca}^{++}$influx by reducing
$\mathrm{N}$-methyl-D-aspartate receptor activation, glutamate neurotoxicity, and oxygen-glucose deprivation neuronal injury in cortical cultures, ${ }^{6}$ as well as hippocampal neurons. ${ }^{7}$

5. In their study, all patients were given methylprednisolone $\left(30 \mathrm{mg} \cdot \mathrm{kg}^{-1}\right.$ ) before undergoing DHCA. Although protective effects of methylprednisolone $\left(30 \mathrm{mg} \cdot \mathrm{kg}^{-1}\right)$ given before ischemia were reported in $1983,{ }^{8} 2$ years later Sapolsky and Pulsinelli reported that even $10 \mathrm{mg} \cdot \mathrm{kg}^{-1}$ of cortisone (glucocorticoids) potentiates ischemic injury to neurons. ${ }^{9}$ To what extent and in which direction the methylprednisolone worked in patients undergoing DHCA is unknown. However, the possibility that the detrimental effect was the dominant effect cannot be ruled out when other conditions are taken into consideration simultaneously.

An equally careful prospective study using $\mathrm{pH}$-stat management may result in longer than the 25-minute dividing time limits observed with alpha-stat strategies or may decrease the relative role of age as a risk factor. The long-debated issue of which blood gas management protocol is preferable during hypothermic perfusion needs to be resolved.

Tadaomi-A. Miyamoto, MD Research Department Kokura Memorial Hospital Kitakyushu, Japan Koho-J. Miyamoto, $M D, P h D$ Assistant Professor

II Department of Physiology University of the Ryukius School of Medicine Okinawa, Japan

\section{REFERENCES}

1. Miyamoto TA, Miyamoto KJ, Ohno N. Objective assessment of CNS function within 6 hours of spinal cord ischemia in rabbits. J Anesth 1998;12:189-94.

2. Miyano $H$, Inagaki $M$, Hashimoto $N$, Shishido $T$, Kawada $T$, Miyake $\mathrm{Y}$, et al. Regional cerebral blood flow during rewarming of cardiopulmonary bypass correlates with posthypothermic regional glucose use. J Thorac Cardiovasc Surg 1998;116:50310.

3. Miyamoto TA, Miyamoto KJ. Regional cerebral blood flow and regional glucose use during rewarming after hypothermic cardiopulmonary bypass. J Thorac Cardiovasc Surg 1999;117: 1228-9.

4. du Plessis AJ, Jonas RA, Wypij D, Hickey PR, Riviello J, Wessel $\mathrm{DL}$, et al. Perioperative effects of alpha-stat versus $\mathrm{pH}$-stat strategies for deep hypothermic cardiopulmonary bypass in infants. $\mathrm{J}$ Thorac Cardiovasc Surg 1997;114:991-1001.

5. Giffard RG, Weiss JH, Choi DW. Extracellular alkalinity exacerbates injury of cultured cortical neurons. Stroke 1992;23:181721.

6. Giffard RG, Monyer H, Christine CW, Choi DW. Acidosis reduces NMDA receptor activation, glutamate neurotoxicity, and oxygen-glucose deprivation neuronal injury in cortical cultures. Brain Res 1990;506:339-42.

7. Tombaugh GC, Sapolsky RM. Mild acidosis protects hippocampal neurons from injury induced by oxygen and glucose deprivation. Brain Res 1990;506:343-5. 
8. Taylor MD, Palmer GC, Callahan AS III. Protective action by methylprednisolone, allopurinol and indomethacin against stroke-induced damage to adenylate cyclase in gerbil cortex. Stroke 1983;15:329-35.

9. Sapolsky RM, Pulsinelli WA. Glucocorticoids potentiate ischemic injury to neurons: therapeutic implications. Science 1985;229:1397-400.

$12 / 8 / 100286$

Reply to the Editor:

We wish to thank Miyamoto and Miyamoto for their thoughtful letter in response to our recent publication regarding neuropsychologic outcome after deep hypothermic circulatory arrest (DHCA). In their discussion of the controversy of $\mathrm{pH}$-stat versus alpha-stat blood gas management, they raised several important issues and ideas for future investigation.

There are several potential explanations for the association between DHCA of more than 25 minutes' duration and late neuropsychologic dysfunction in our study. Although we can- not rule out alpha-stat management, we believe that factors such as longer cerebral ischemia, more complex aortic repairs, and more advanced atheromatous disease in elderly patients were more likely causes. Additionally, the extrapolation of animal models of neuronal protection to the clinical scenario of adult aortic reconstruction is problematic.

We have no immediate plans to use $\mathrm{pH}$-stat blood gas management in patients undergoing DHCA for aortic reconstruction. We firmly believe, however, that improved modalities of cerebral protection will arise eventually from experimental models and clinical investigation, including the important contributions of Miyamoto and Miyamoto, among others.

David L. Reich, MD Professor of Anesthesiology Mount Sinai School of Medicine One Gustave L. Levy Place New York, NY 10029-6574

12/8/100287

\section{Timely}

The Journal of Thoracic and Cardiovascular Surgery delivers the information you need now. Articles usually appear within four months of acceptance. 